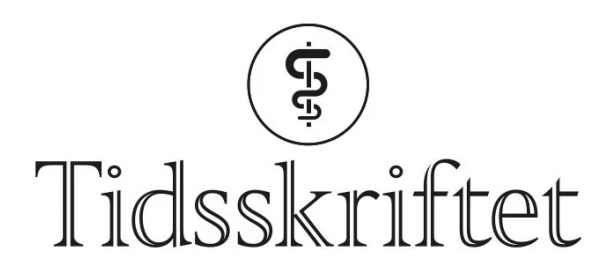

DEN NORSKE LEGEFORENING

\title{
Epifysiolyse av lårbenshodet
}

\author{
KLINISK OVERSIKT
}

\section{ANDERS WENSAAS}

anders.wensaas@ous-hf.no

Seksjon for barneortopedi og rekonstruktiv kirurgi

Oslo universitetssykehus, Rikshospitalet

Anders Wensaas er spesialist i ortopedisk kirurgi, overlege og dr.philos. på en avhandling om

epifysiolysis capitis femoris.

Forfatteren har fylt ut ICMJE-skjemaet og oppgir ingen interessekonflikter.

\section{TERJE TERJESEN}

Seksjon for barneortopedi og rekonstruktiv kirurgi

Oslo universitetssykehus, Rikshospitalet

Terje Terjesen er spesialist i ortopedisk kirurgi og professor emeritus.

Forfatteren har fylt ut ICMJE-skjemaet og oppgir ingen interessekonflikter.

\section{Epifysiolysis capitis femoris er en barnehoftesykdom som} rammer om lag 30 barn i Norge hvert år. Symptomene er halting og smerter i hofte eller kne. Diagnosen stilles ut fra vanlig røntgen, og behandlingen er kirurgisk. Det er viktig å stille diagnosen så raskt som mulig, og barn med vedvarende hoftesymptomer bør raskt undersøkes med røntgen.

Ved epifysiolysis capitis femoris, epifysiolyse av lårbenshodet, skjer det en glidning i vekstskiven (epifyseskiven) mellom lårbenshodet (epifysen) og lårhalsen (metafysen) øverst i lårbenet (figur 1, figur 2). Gjennomsnittsalderen ved diagnose er 12 år for jenter og 13 år for gutter. Tilstanden forekommer utelukkende så lenge epifyseskiven er åpen, og meget sjeldent ved alder under 9 år og over 16 år. Om lag 25 \% får glidning i begge hoftene. 


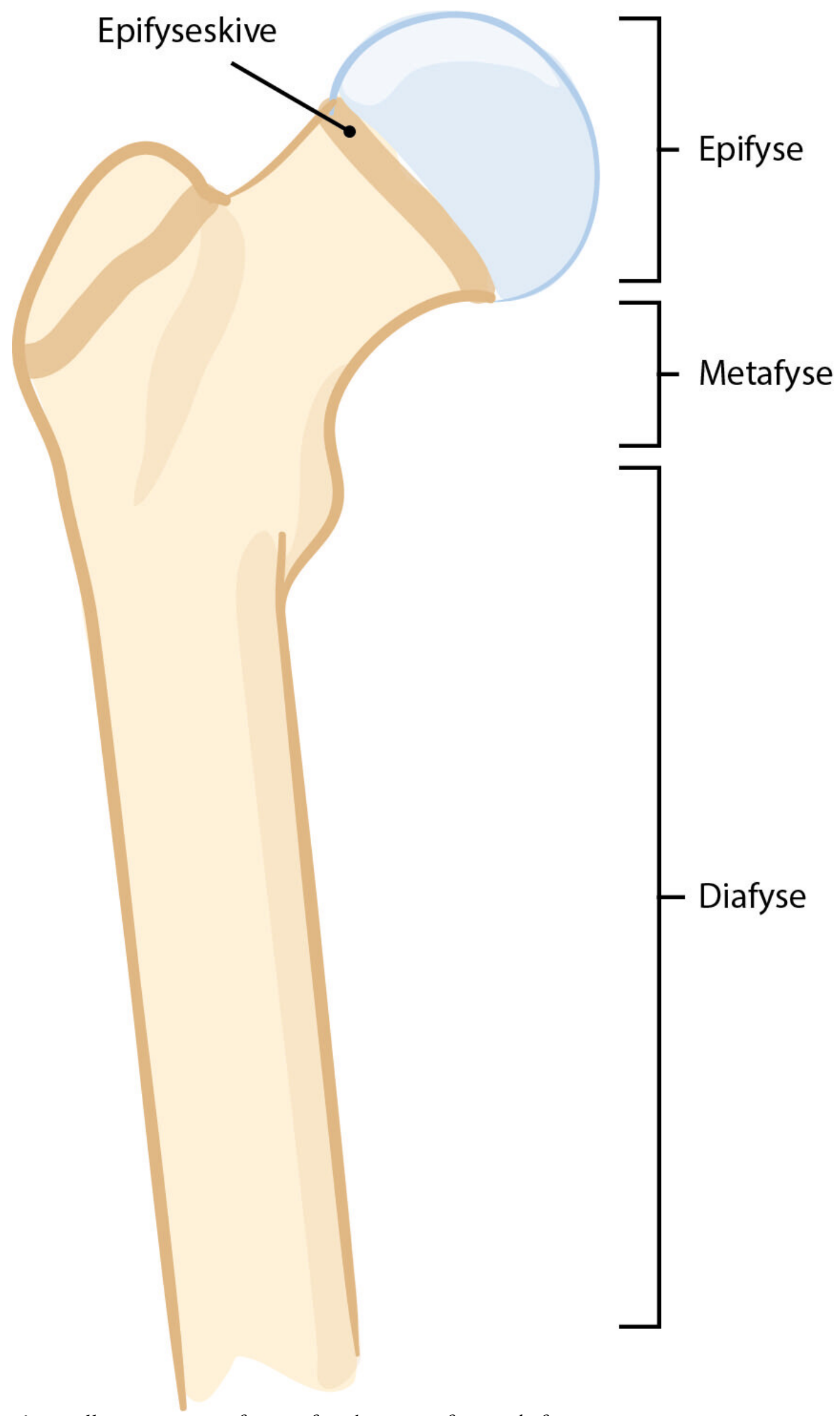

Figur 1 Illustrasjon av epifyse, epifyseskive, metafyse og diafyse. 


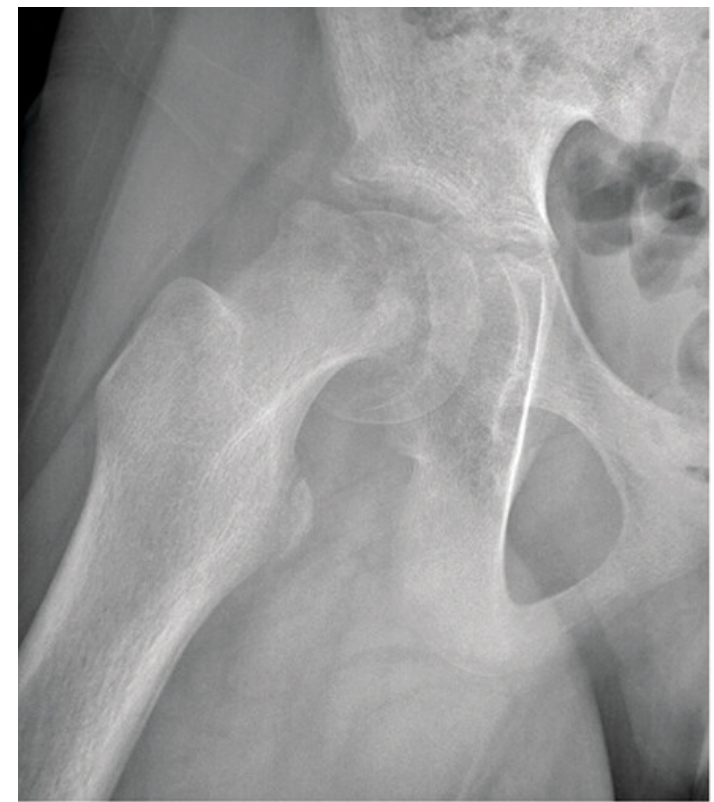

a

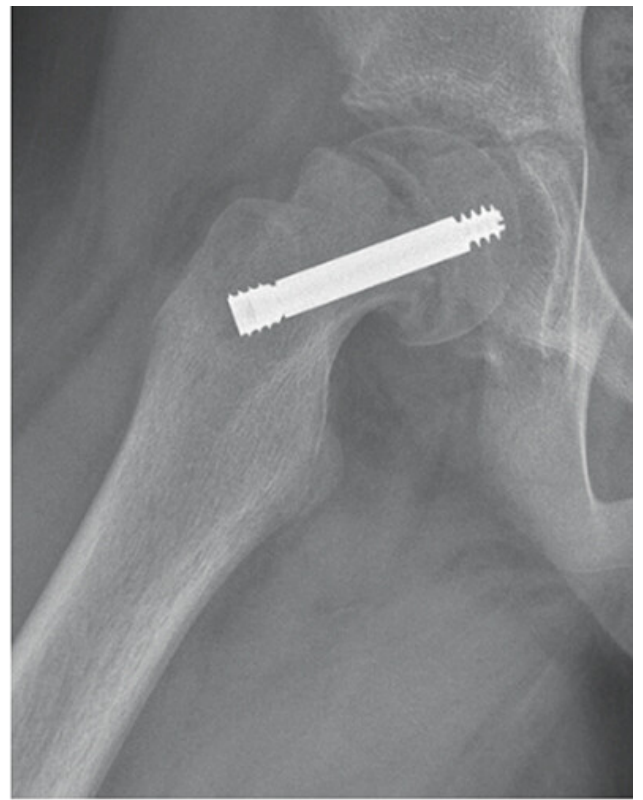

b

Figur 2 Høyresidig ustabil epifysiolysis capitis femoris behandlet med skruefiksasjon. En del av feilstillingen reponerte seg spontant under operasjon. a) Røntgen preoperativt og b) røntgen postoperativt etter fiksasjon med teleskoperende skrue som tillater fortsatt vekst. Årsaken til tilstanden er ukjent. Symptomene er hoftesmerter, eventuelt knesmerter og halting. Diagnosen stilles ut fra vanlig røntgenundersøkelse av hoftene. Det er viktig å stille diagnosen så raskt som mulig, ettersom glidningen øker og prognosen forverres uten behandling (1). Behandlingen er kirurgisk stabilisering av epifyseskiven med mål om å gjøre pasienten symptomfri og hindre ytterligere glidning. Gjennomgått epifysiolyse gir

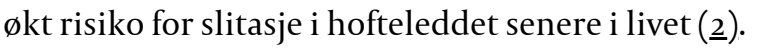

Vi vil i denne artikkelen gi en oversikt over denne barnehoftesykdommen, basert på et skjønnsmessig utvalg av litteratur i tillegg til egen forskning og klinisk erfaring.

\section{Årsak og epidemiologi}

Årsaken til epifysiolysis capitis femoris er i de fleste tilfeller ukjent. Den mest utbredte oppfatningen er at det foreligger en kombinasjon av biomekaniske og biokjemiske faktorer. Retroversjon av acetabulum og femur samt økt vertikal helning på epifyseskiven har i studier vist å være assosiert med sykdommen, som også er sterkt assosiert med høy kroppsmasseindeks. Risikoen for epifysiolysis capitis femoris er økt ved noen sjeldne endokrinologiske sykdommer (hypothyreose, veksthormonmangel, hypogonadisme), metabolske tilstander som renal osteodystrofi og gjennomgått stråle- eller kjemoterapi. Det er funnet assosiasjon med forhøyete nivåer av insulin og leptin $(3,4$. .).

Epifysiolysis capitis femoris oppstår i prepubertet når det er økt lengdevekst og flere hormonelle endringer, og kan muligens skyldes en endokrinologisk tilstand som ikke er kartlagt ennå.

Internasjonalt er det stor forskjell i rapportert forekomst av epifysiolysis capitis femoris. I Barnehofteregisteret i Norge var det 266 nye tilfeller fra og med 2010 til og med 2018 (6,8 per år per 100 ooo barn per år i alderen 9-15 år). Årsaken til den store variasjonen i rapportert forekomst er ukjent, men etnisitet ser ut til å ha betydning (5).

\section{Diagnose}


De fleste pasienter med epifysiolysis capitis femoris har hoftesmerter og halting. Noen pasienter har knesmerter. Hvis man ikke kjenner sammenhengen mellom knesmerter og hoftepatologi hos barn, vil diagnostiseringen kunne bli forsinket (1). Det er derfor svært viktig at man undersøker hoftene på barn med knesmerter. Terskelen for røntgenundersøkelse av hoftene ved knesmerter hos barn bør være lav.

I Norge har pasienter med epifysiolysis capitis femoris i gjennomsnitt hatt symptomer i fem måneder før diagnosen stilles, og det ser ut til å være uendret gjennom de siste 50 årene (므). Dette er uheldig fordi glidningen $\emptyset$ ker og prognosen forverres uten behandling. I starten kan symptomene være lette, og «lyskestrekk» er ikke sjelden en feildiagnose som blir stilt.

Ved klinisk undersøkelse vil det være redusert innadrotasjon i den affiserte hoften. Hofterotasjon måles med barnet i mageleie med strake hofter og $90^{\circ}$ fleksjon i knærne (figur 3). Mens bekkenet stabiliseres, roteres leggen ut (innadrotasjon av hoften) og inn (utadrotasjon av hoften). Nedre normale grense for innadrotasjon hos 11-åringer er ca. $30^{\circ}$ (吕).

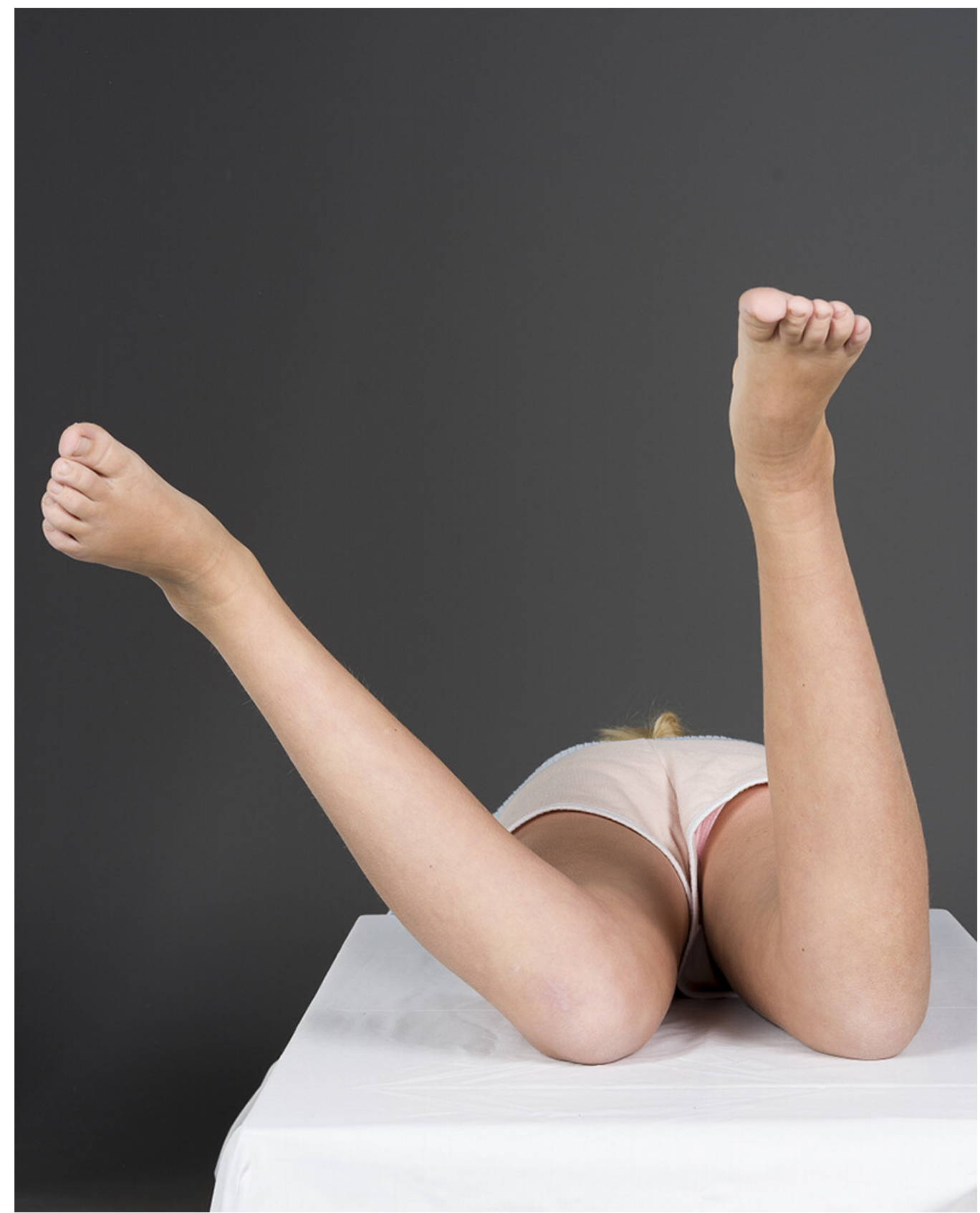

Figur 3 Høyresidig ECF. Klinisk undersøkelse av hofterotasjon med strake hofter og $90^{\circ}$ fleksjon i knærne viser nedsatt innadrotasjon i affisert høyre hofte. Foto: Ine Eriksen, Universitetet i Oslo. 
Diagnosen stilles ved vanlig røntgenundersøkelse av hoftene. Det er viktig at det er tatt adekvate sidebilder av begge hofter for å sammenligne dem, fordi lette glidninger kan være vanskelig å oppdage kun på frontbilde. Når det er klinisk mistanke om epifysiolysis capitis femoris og normale funn på røntgenbildene, bør barnet utredes med MR-undersøkelse. Dette kan avdekke begynnende glidning samt avklare andre årsaker til hoftesmerter. I tillegg til selve glidningen vil MR vise breddeøkning av epifyseskiven, benmargsødem over og under epifyseskiven og $ø$ kt mengde leddvæske (.7.).

Barnehoftesykdommen Calvé-Legg-Perthes' sykdom (aseptisk nekrose av epifysen), som forekommer noe hyppigere enn epifysiolysis capitis femoris, vil være en differensialdiagnose hos yngre pasienter under 12 år. De to tilstandene skilles imidlertid lett fra hverandre på grunnlag av røntgenfunn.

\section{Klassifikasjon}

Dagens kliniske klassifikasjon skiller mellom stabil og ustabil epifysiolysis capitis femoris. Hvis pasienten klarer å vektbelaste med eller uten krykker, klassifiseres glidningen som stabil, og hvis pasienten ikke klarer å vektbelaste, er det en ustabil glidning (모). Radiologisk måles graden av glidning på sidebilde (figur 4 ). Glidning på $<30^{\circ}$ klassifiseres som lett, $30-$ $50^{\circ}$ som moderat og $>50^{\circ}$ som betydelig.

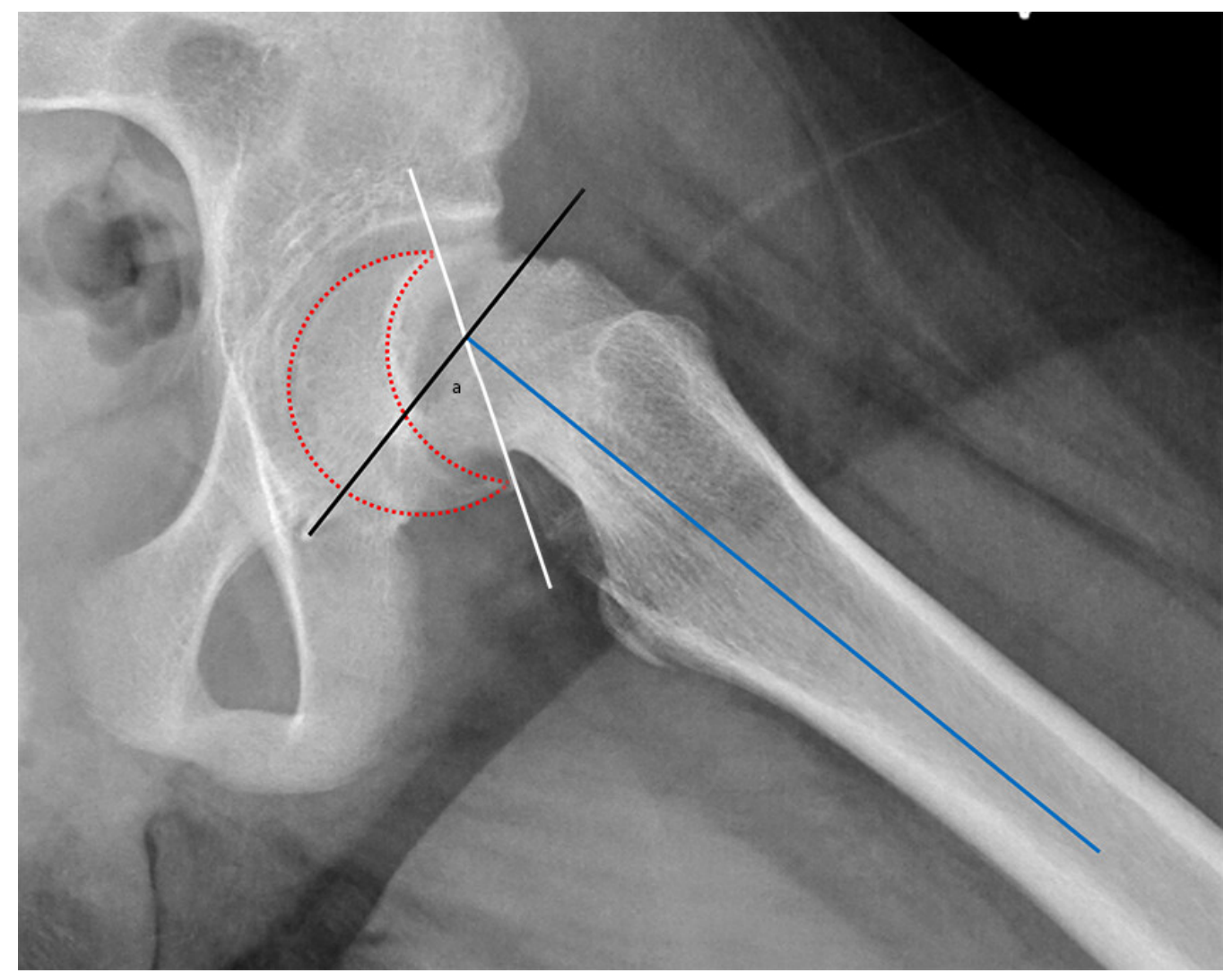

Figur 4 Glidningsvinkelen (a) måles på sidebilde (epifysen er markert med stiplet linje) og er vinkelen mellom epifyseskiven (hvit linje) og en linje (svart linje) vinkelrett på lengdeaksen i femur (blå linje). Normalt skal denne vinkelen være $<12^{\circ}$.

\section{Bilateral epifysiolyse}

5-10 \% av pasientene vil ha bilateral sykdom ved primærdiagnose, og ved unilateral sykdom vil om lag $25 \%$ få kontralateral glidning i forløpet frem til de er utvokst. Profylaktisk fiksasjon av den kontralaterale hoften ved unilateral epifysiolyse er omdiskutert, først og fremst fordi $75 \%$ vil bli operert unødvendig, med en viss risiko for komplikasjoner. 
I Norge har det ikke vært tradisjon for rutinemessig profylaktisk fiksasjon. Ved enkelte endokrinologiske og metabolske tilstander (9) eller når pasienten er svært ung ( $<10$ år for jenter $0 \mathrm{~g}<11$ år for gutter) (10 $)$, er risikoen for kontralateral glidning $\varnothing \mathrm{kt}$. Profylaktisk fiksasjon bør i slike tilfeller vurderes individuelt.

\section{Behandling}

Standard behandling er operativ stabilisering av epifyseskiven. Hensikten er å gjøre pasienten symptomfri samt hindre ytterligere glidning. Epifyseskiven stabiliseres in situ, det vil si man gjør ingen forsøk på å reponere glidningen. Imidlertid vil en del av feilstillingen kunne reponere seg spontant ved ustabil epifysiolysis capitis femoris i forbindelse med leiring under operasjon (figur 2). Grunnen til at det ikke skal gjøres noe aktivt fors $\emptyset \mathrm{k}$ på reponering er at det gir $\emptyset \mathrm{kt}$ risiko for skade på blodforsyningen til epifysen, med fare for caputnekrose som komplikasjon (1ㅡ).

Prosedyren er perkutan, har få komplikasjoner og krever kortvarig innleggelse. Vi anbefaler at det benyttes skrue som tillater fortsatt vekst i epifyseskiven, da dette vil

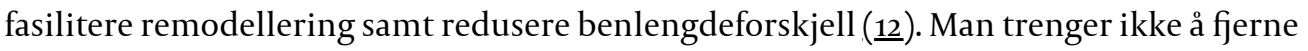
skruen senere med mindre den gir kliniske plager.

For rundt ti år siden ble det lansert en ny behandlingsmetode fra Sveits for større glidninger der hoften lukseres ut av ledd med åpen korreksjon av glidningen før fiksering (13). Det attraktive ved denne metoden er at feilstillingen kan rettes opp til tilnærmet anatomisk stilling med sannsynlig lavere risiko for senere hofteplager.

Hovedinnvendingen mot metoden er risiko for caputnekrose. Fra dem som lanserte metoden, ble det rapportert om gode resultater og lav forekomst av caputnekrose, men etter hvert som metoden har blitt mer utbredt, er det publisert flere studier der det rapporteres om caputnekrose hos $20-30 \%$ av pasientene (14). Metoden brukes ikke rutinemessig i Norge på grunn av risikoen for caputnekrose.

Etter in situ-fiksasjon vil feilstillingen i noen grad remodelleres, med videre vekst. Men spesielt ved betydelige glidninger kan den permanente deformiteten i overgangen mellom caput og collum gi plager, idet den stanger mot kanten av acetabulum (femoroacetabulær inneklemming) (figur 5). Det kan da være aktuelt med kirurgisk behandling der man korrigerer feilstillingen i øvre del av femur eller fjerner deformiteten i overgangen mellom caput og collum (15). Pasienter med vedvarende hofteplager etter epifysiolysis capitis femoris skal derfor henvises til ortopedisk avdeling med spesialkompetanse i barneortopedi. 


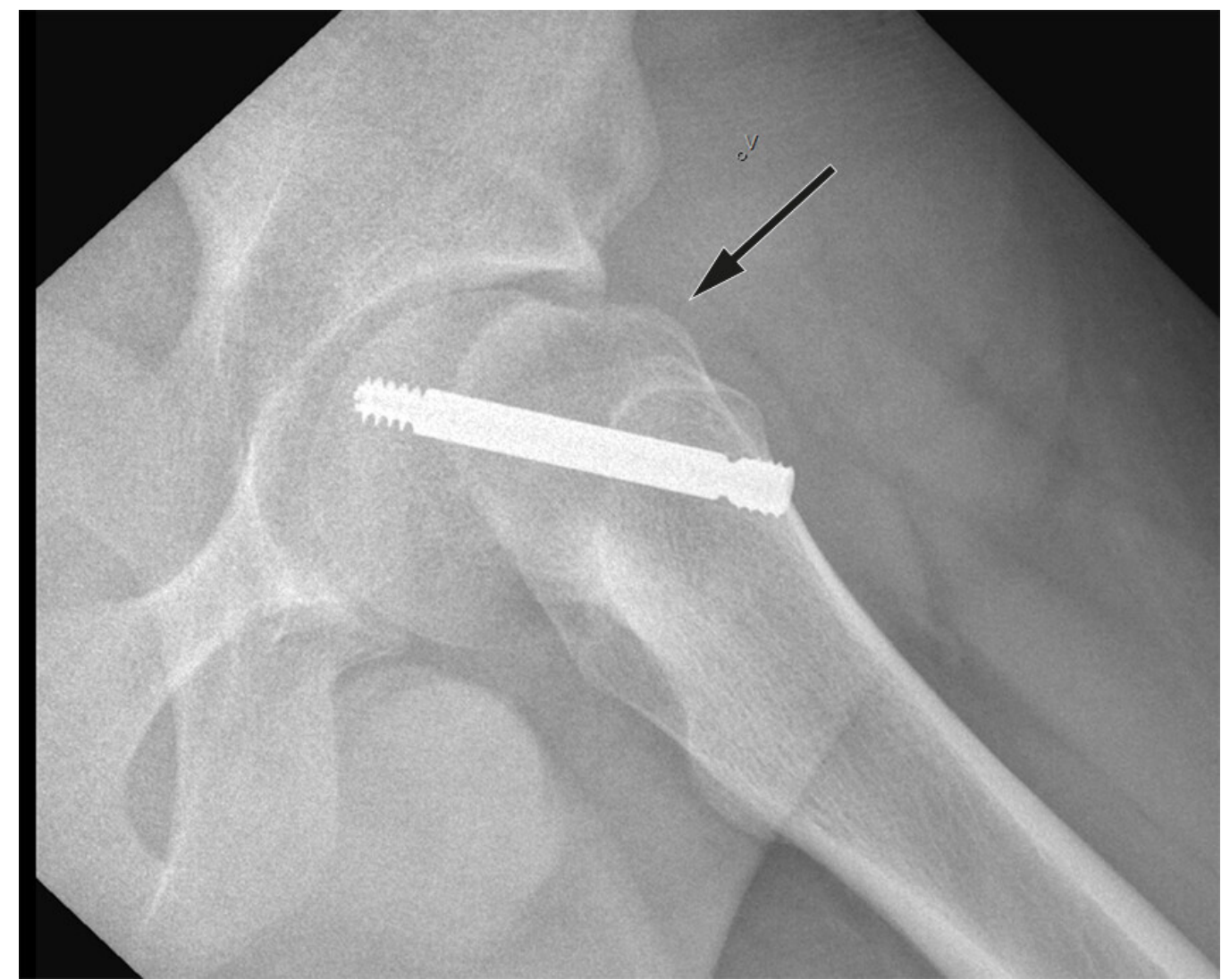

Figur 5 Venstresidig epifysiolysis capitis femoris primært behandlet med in situ-fiksasjon ett år tidligere. Klinisk og radiologisk femoroacetabulær inneklemming (svart pil).

\section{Prognose}

Den mest alvorlige komplikasjonen til epifysiolysis capitis femoris er caputnekrose, som forekommer nesten utelukkende ved ustabile glidninger. Årsaken til affeksjon av blodforsyningen til epifysen kan være direkte skade, eventuelt at blodkarene kommer i klem i forbindelse med selve glidningen, tamponade på grunn av økt intraartikulært trykk (hemartros) eller skade på blodkarene ved forsøk på reponering.

De fleste pasienter vil få betydelige hoftesmerter, og behandlingen er hofteprotese. Persisterende deformitet kan gi femoroacetabulær inneklemming og på lengre sikt økt risiko for artrose. I en langtidsoppfølgingsstudie av 66 pasienter ( 76 hofter) operert ved Sophies Mindes hospital med gjennomsnittlig oppfølging på 38 år, hadde 14 pasienter (16 hofter) blitt behandlet med hofteprotese (gjennomsnittsalder 48 år). 69\% av dem som ble behandlet med in situ- fiksasjon, hadde et godt resultat (Harris' hofteskår $\geq 85$ poeng) ved oppfølging (2.2). Det var en tydelig assosiasjon mellom røntgenologisk deformitet etter epifysiolyse og langtidsresultatet (므).

Nasjonalt barnehofteregister ble opprettet i 2010, og alle nye tilfeller av epifysiolysis capitis femoris blir registrert her.

\section{Oppsummering}

Barn med hofteplager og halting skal alltid utredes raskt med røntgenundersøkelse. I aldersgruppen 9-16 år er barnehoftesykdommen epifysiolysis capitis femoris en vanlig årsak. Ved knesmerter hos barn er det viktig å kjenne til at dette kan være referert smerte fra hofteleddet. Redusert hofteinnadrotasjon i mageleie er viktigste kliniske funn. Forsinket diagnostikk gir dårligere prognose. Behandling er alltid kirurgisk, og standardoperasjonen er perkutan in situ-fiksasjon med en skrue. Om lag $25 \%$ vil få glidning 
i den kontralaterale hoften før de er utvokst. Ved vedvarende hofteplager skal pasienten henvises til ortopedisk avdeling med barneortopedisk kompetanse. På sikt vil pasienter med gjennomgått epifysiolysis capitis femoris ha økt risiko for hofteleddsartrose.

Pasienten og pasientens foresatte har gitt samtykke til at artikkelen blir publisert.

\section{LITTERATUR}

1. Herngren B, Stenmarker M, Vavruch L et al. Slipped capital femoral epiphysis: a population-based study. BMC Musculoskelet Disord 2017; 18:304. [PubMed][CrossRef]

2. Wensaas A, Svenningsen S, Terjesen T. Long-term outcome of slipped capital femoral epiphysis: a 38-year follow-up of 66 patients. J Child Orthop 2011; 5: 75-82. [PubMed][CrossRef]

3. Montañez-Alvarez M, Flores-Navarro HH, Cuevas-De Alba C et al. The role of hyperinsulinemia in slipped capital femoral epiphysis. J Pediatr Orthop 2020; 40: 413-7. [PubMed][CrossRef]

4. Halverson SJ, Warhoover T, Mencio GA et al. Leptin elevation as a risk factor for slipped capital femoral epiphysis independent of obesity status. J Bone Joint Surg Am 2017; 99: 865-72. [PubMed] [CrossRef]

5. Loder RT. The demographics of slipped capital femoral epiphysis. An international multicenter study. Clin Orthop Relat Res 1996; 322: 8-27. [PubMed][CrossRef]

6. Svenningsen S, Terjesen T, Auflem M et al. Hip rotation and in-toeing gait. A study of normal subjects from four years until adult age. Clin Orthop Relat Res 1990; nr. 251:177-82. [PubMed]

7. Wensaas A, Wiig O, Hellund JC et al. Magnetic resonance imaging at primary diagnosis cannot predict subsequent contralateral slip in slipped capital femoral epiphysis. Skeletal Radiol 2017; 46: 1687-94. [PubMed][CrossRef]

8. Loder RT, Richards BS, Shapiro PS et al. Acute slipped capital femoral epiphysis: the importance of physeal stability. J Bone Joint Surg Am 1993; 75: 1134-40. [PubMed][CrossRef]

9. Loder RT, Wittenberg B, DeSilva G. Slipped capital femoral epiphysis associated with endocrine disorders. J Pediatr Orthop 1995; 15:349-56. [PubMed][CrossRef]

10. Riad J, Bajelidze G, Gabos PG. Bilateral slipped capital femoral epiphysis: predictive factors for contralateral slip. J Pediatr Orthop 2007; 27: 411-4. [PubMed][CrossRef]

11. Carney BT, Weinstein SL, Noble J. Long-term follow-up of slipped capital femoral epiphysis. J Bone Joint Surg Am 1991; 73: 667-74. [PubMed][CrossRef]

12. Örtegren J, Björklund-Sand L, Engbom $M$ et al. Continued growth of the femoral neck leads to improved remodeling after in situ fixation of slipped capital femoral epiphysis. J Pediatr Orthop 2018; 38: 170-5. [PubMed][CrossRef]

13. Ziebarth K, Zilkens C, Spencer S et al. Capital realignment for moderate and severe SCFE using a modified Dunn procedure. Clin Orthop Relat Res 2009; 467: 704-16. [PubMed][CrossRef]

14. Davis RL, Samora WP, Persinger F et al. Treatment of unstable versus stable slipped capital femoral epiphysis using the modified Dunn procedure. J Pediatr Orthop 2019; 39: 411-5. [PubMed][CrossRef]

15. Baraka MM, Hefny HM, Thakeb MF et al. Combined Imhauser osteotomy and osteochondroplasty in slipped capital femoral epiphysis through surgical hip dislocation approach. J Child Orthop 2020; 14:190-200. [PubMed][CrossRef]

16. Wensaas A, Gunderson RB, Svenningsen S et al. Femoroacetabular impingement after slipped upper femoral epiphysis: the radiological diagnosis and clinical outcome at long-term follow-up. J Bone Joint Surg Br 2012; 94: 1487-93. [PubMed][CrossRef]

Publisert: 22. november 2021. Tidsskr Nor Legeforen. DOI:10.4045/tidsskr.20.1035

Mottatt 18.12.2020, første revisjon innsendt 27.8.2021, godkjent 20.9.2021.

Publisert under åpen tilgang CC BY-ND. Lastet ned fra tidsskriftet.no 26. april 2023. 